\title{
Bioinformatics analysis of the expression and role of microRNA-221-3p in head and neck squamous cell carcinoma
}

Ziyan Zhou ${ }^{1,2 \dagger}$, Wenling Wu ${ }^{3 \dagger}$, Jixi Li ${ }^{1,2}$, Chang Liư ${ }^{4}$, Zixi Xiao ${ }^{4}$, Qinqiao Lai ${ }^{4}$, Rongxing Qin ${ }^{4}$, Mingjun Shen ${ }^{1,2}$, Shuo Shi ${ }^{5}$ and Min Kang ${ }^{1,2^{*}}$

\begin{abstract}
Background: Head and neck squamous cell carcinoma (HNSCC) is the sixth most common cancer worldwide, associated with a high rate of morbidity and mortality. However, the target genes of miR-221-3p and the underlying mechanism involved in HNSCC are still not clear. Therefore, in the current study, we studied the role of miR-221-3p in the HNSCC.

Methods: Tissues collected from 48 control and 21 HNSCC patients were processed to check the differential expression of miR-221-3p by RT-qPCR. Overexpression of microRNA-221-3p (miR-221-3p) is significantly correlated to the onset and progression of HNSCC. We also conducted the meta-analysis of the cancer literature from the cancer genome atlas (TCGA) and the Gene Expression Omnibus (GEO) database to estimate the expression of miR-221-3p in HNSCC. The miR-221-3p target genes in the HNSCC were predicted with the miRWalk and TCGA databases, and functionally annotated via the Gene Ontology. Finally, Spearman's analysis was used to determine the role of the related target genes in important pathways involved in the development of HNSCC.

Results: We observed a significantly higher expression of miR-221-3p in HNSCC compared to the normal with a summary receiver operating characteristic (sROC) of $0.86(95 \% \mathrm{Cl}: 0.83,0.89)$. The KEGG and GO comprehensive analysis predicted that miR-221-3p might be involved in the development of HNSCC through the following metabolic pathways, viz. Drug metabolism - cytochrome P450 UGT1A7 and MAOB may be important genes for the role of miR-221-3p.

Conclusion: Based on bioinformatics analysis, our results indicate that miR-221-3p may be used as a non-invasive and hypersensitive biomarker in the diagnosis. Thus, it can be concluded that miR-221-3p may be an extremely important gene locus involved in the process of the deterioration and eventual tumorigenesis of HNSCC. Hopefully, additional work will validate its usefulness as a target for future clinical research.
\end{abstract}

Keywords: HNSCC, miR-221-3p, RT-qPCR, TCGA, Bioinformatics

\footnotetext{
*Correspondence: kangmin@gxmu.edu.cn

'Ziyan Zhou and Wenling Wu contributed equally to this work.

${ }^{1}$ Department of Radiation Oncology, Guangxi Medical University First Affiliated Hospital, Nanning 530021, Guangxi, People's Republic of China

${ }^{2}$ Guangxi Tumor Radiation Therapy Clinical Medical Research Center, Nanning 530021, Guangxi, People's Republic of China

Full list of author information is available at the end of the article
}

(C) The Author(s). 2021 Open Access This article is licensed under a Creative Commons Attribution 4.0 International License, which permits use, sharing, adaptation, distribution and reproduction in any medium or format, as long as you give appropriate credit to the original author(s) and the source, provide a link to the Creative Commons licence, and indicate if changes were made. The images or other third party material in this article are included in the article's Creative Commons licence, unless indicated otherwise in a credit line to the material. If material is not included in the article's Creative Commons licence and your intended use is not permitted by statutory regulation or exceeds the permitted use, you will need to obtain permission directly from the copyright holder. To view a copy of this licence, visit http://creativecommons.org/licenses/by/4.0/ The Creative Commons Public Domain Dedication waiver (http://creativecommons.org/publicdomain/zero/1.0/) applies to the data made available in this article, unless otherwise stated in a credit line to the data. 


\section{Background}

Head and neck squamous cell carcinoma (HNSCC), encompassing oral squamous cell carcinoma, oropharyngeal squamous cell carcinoma, hypopharyngeal squamous cell carcinoma and laryngeal squamous cell carcinoma, is the sixth most common cancer worldwide, accounting for approximately $1-2 \%$ of all cancer deaths, with approximately 600,000 new cases detected each year globally [1-3]. The treatment of patients at the early stage is relatively successful, but the overall survival rate of recurrent or metastatic HNSCC remains low and has barely seen any improvements for decades [4, 5]. Although the past three decades have seen several improvements in diagnostic tools and treatment regimens, the overall survival rate for advanced (stage III-IV) HNSCC is only $65 \%$ $[6,7]$. The current standard of care for such patients is surgery along with radiation and chemotherapy, but these have not significantly improved the 5-year survival of HNSCC patients. The main reason for the decline in patient survival is the lack of effective therapeutic targets for the development of HNSCC $[8,9]$.

Recent years have seen an increasing concentration of research on microRNAs (miRNAs) [10,11], which are a type of highly conserved single-stranded noncoding RNA containing $17 \sim 22$ nucleotides and are involved in the process of tumorigenesis, cell survival, and chemosensitivity [12-14]. They bind to the 3 ' untranslated region (3'UTR) of different target mRNA (messenger RNA) genes to degrade or inhibit the mRNA translation of target genes associated with a tumor suppressor function $[13,15,16]$. In normal healthy individuals, miR$221-3 p$ is observed to play a role in the process of vascular proliferation [17], while the tumor promoter microRNA-221 is involved in the process of regulating apoptosis of tumor cells [18-20] and is associated with a variety of cancer types, including hepatocellular cancer [21], cutaneous melanoma [19], prostate cancer [20], and non-small cell lung cancer [22].

Studies have shown that specific miRNA profiles can be identified between tumor tissue and adjacent healthy tissue in HNSCC patients [2, 23]. For instance, studies have reported a link between miR-221 and vascular invasion in HNSCC $[14,15,24-26]$. However, the definite target gene of miR-221-3p and its biological mechanism of action are still not clear. Thus, in the current study, we investigated the expression of miR-221-3p in HNSC $\mathrm{C}$ and attempted to explore the correlation between the two.

\section{Methods}

\section{RT -qPCR}

Tissue specimens were collected from 48 control and 21 HNSCC patients from the Department of Pathology, First Affiliated Hospital of Guangxi Medical University
(Nanning, Guangxi Medical University). Total RNA was extracted from formalin-fixed, paraffin-embedded (FFPE) tissues using an FFPE RNA kit (Omega Bio-Tek, Norcross, GA, USA). RNA was reverse-transcribed into cDNA using the Mir-X miRNA qRT-PCR SYBR Kit (Takara, California, USA). The cDNA samples were processed for qPCR with SYBR-Green Master Mix (Takara, Tokyo, Japan) on an ABI 7500 cycler (Applied Biosystems) under the following conditions: initial denaturation at $95^{\circ} \mathrm{C}$ for $30 \mathrm{~s}$, followed by 40 cycles of denaturation at $95^{\circ} \mathrm{C}$ for $5 \mathrm{~s}$ and annealing at $60^{\circ} \mathrm{C}$ for 34 s. The expression of miR-221-3p in HNSCC tissues relative to negative control (NC) tissues was calculated using the 2- $\Delta \Delta \mathrm{CT}$ method, with U6 as the internal control. The primers for miR-221-3p and U6 were synthesized by TaKaRa (Dalian, Liaoning, China), and the sequences were as follows: miR-221-3p: forward 5'-AGCUAC AUUGUCUGCUGGGUUUC - 3' and reverse $5^{\prime} \mathrm{mRQ}$ 3'; U6: forward 5'-GGAACGATACAGAGAAGATTAG C-3' and reverse 5'-TGGAACGCTTCACGAATT TGCG-3'. All the experiments were repeated three times.

\section{Literature search and selection strategy}

A literature search was conducted in PubMed, Chinese Biomedical Literature Database (CBM), Science Direct, China National Knowledge Infrastructure (CNKI) database, Web of Science, Wiley Online Library, EMBASE, China Science and Technology Journal Database (VIP) and Wanfang Database for this study. We searched the databases from the earliest available data to October 1, 2019. The following keywords were used: (HNSCC OR

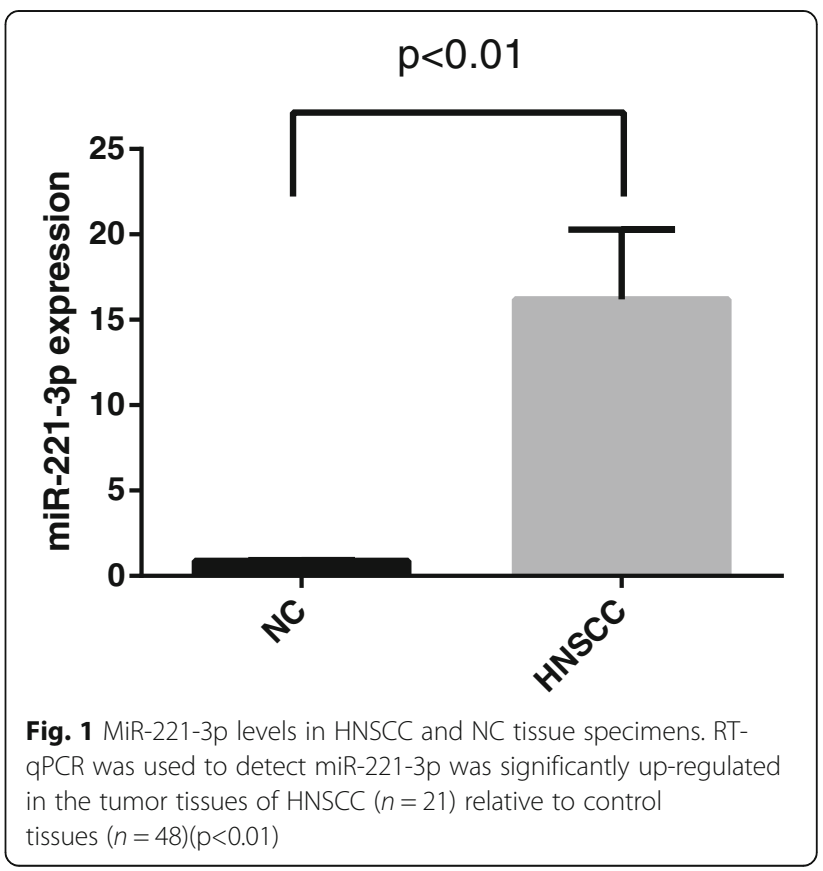




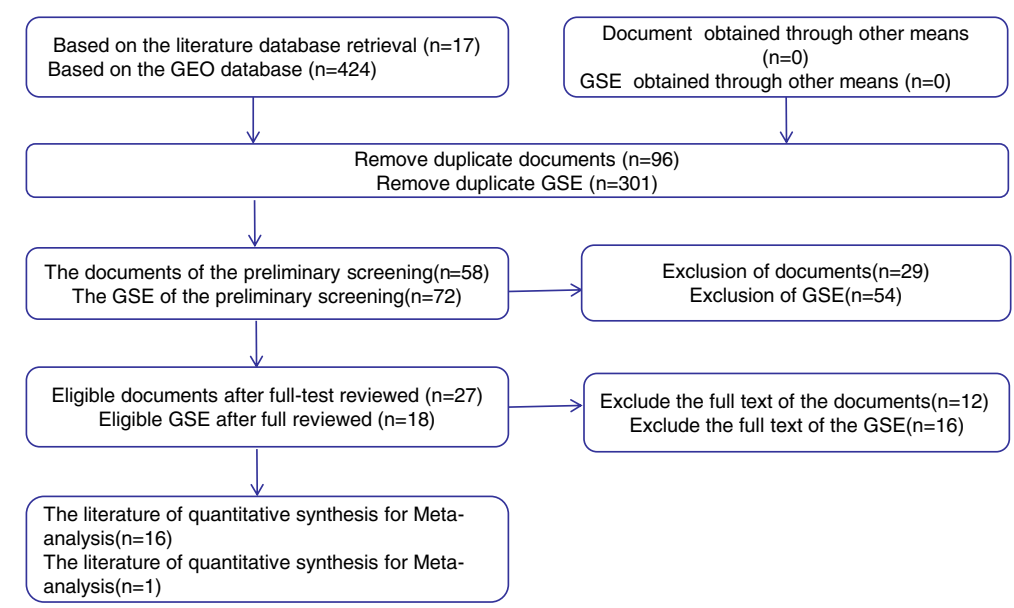

Fig. 2 The flow chart of literature search and selection of relevant studies. Sixteen out of 424 GEO microarray datasets met our inclusion criteria. At the same time, a total of 17 articles were retrieved from the initial search, and one papers (Zhou Cheng. et al) were selected after the full-text review based on the inclusion criteria

SCC OR "squamous cell cancer" OR "squamous cell carcinoma") AND (oropharynx OR oropharyngeal OR "head and neck" OR nose OR nasopharynx OR "nasal sinus" OR "nasal cavity" OR "oral cavity" OR hypopharynx OR oral OR laryngopharynx OR larynx OR laryngopharyngeal OR laryngeal OR pharyngeal OR tongue OR tonsil OR tonsillar OR cheek OR palatal OR "paranasal sinuses" OR buccal OR lip) AND (microRNA-221-3p OR miRNA-221-3p OR "miR 221-3p" OR "miRNA 2213p" OR miRNA221-3p OR miR221-3p).

\section{Selection criteria and data extraction}

The databases were searched independently by two researchers who selected the studies based on the following inclusion criteria: (1) comparison of HNSCC and noncancerous tissues; (2) validation of miR-221-3p expression levels via reverse transcription quantitative PCR (RT-qPCR); (3) evaluation of the association between miR-221-3p expression and clinical outcomes; and (4) availability of sufficient data to calculate the mean, standard deviation (SD) and 95\% confidence intervals

Table 1 The main features of included studies for this meta-analysis

\begin{tabular}{|c|c|c|c|c|c|}
\hline Researcher & Year & Country & Cancer/normal & Methods & Sample \\
\hline TCGA & 2019 & USA & $523 / 44$ & $\mathrm{qPCR}$ & Tissue \\
\hline GSE11163 & 2012 & USA & $16 / 5$ & qPCR & Tissue \\
\hline GSE103931 & 2018 & Taiwan & $30 / 19$ & $\mathrm{qPCR}$ & Tissue \\
\hline GSE107591 & 2018 & USA & $24 / 23$ & $q P C R$ & Tissue \\
\hline GSE113956 & 2019 & China & $25 / 15$ & $\mathrm{qPCR}$ & Tissue \\
\hline GSE28100 & 2015 & USA & $17 / 3$ & qPCR & Tissue \\
\hline GSE31277 & 2018 & Brazil & $15 / 15$ & qPCR & Tissue \\
\hline GSE34496 & 2017 & USA & $44 / 25$ & qPCR & Tissue \\
\hline GSE45238 & 2019 & USA & $40 / 40$ & qPCR & Tissue \\
\hline GSE51829 & 2013 & China & $4 / 4$ & qPCR & Tissue \\
\hline GSE58911 & 2018 & USA & $15 / 15$ & $q P C R$ & Tissue \\
\hline GSE69002 & 2017 & USA & $3 / 4$ & qPCR & Tissue \\
\hline GSE70289 & 2018 & USA & $12 / 4$ & $q P C R$ & Tissue \\
\hline GSE73171 & 2017 & Hong Kong & $3 / 3$ & $q P C R$ & Tissue \\
\hline GSE75630 & 2016 & Australia & $28 / 18$ & $\mathrm{qPCR}$ & Tissue \\
\hline GSE82064 & 2017 & Switzerland & $78 / 18$ & qPCR & Tissue \\
\hline GSE98463 & 2018 & Spain & $8 / 8$ & $q P C R$ & Tissue \\
\hline Zhou Cheng. et al & 2019 & China & $26 / 26$ & qPCR & Tissue \\
\hline
\end{tabular}


(95\% CIs). The articles were eliminated if they met any of the following exclusion criteria: (1) irrelevant to the research focus; (2) inclusion of unqualified data; (3) publication language other than English or Chinese; (4) overlapping or duplicate publications; and (5) letters, reviews, comments, editorials, conference articles, laboratory studies or case reports. The reviewers independently appraised the quality of data in each eligible study and extracted the first author name, year of publication, country of origin, sample type, sample size and analysis method. For articles with incomplete information, the authors were contacted to obtain relevant information.

\section{Microarray data collection from GEO}

The microarray data of HNSCC samples uploaded until October 1, 2019, were obtained from the GEO database (https://www.ncbi.nlm.nih.gov/gds/) using the following keywords: (HNSCC OR SCC OR "squamous cell cancer" OR "squamous cell carcinoma") AND (oropharynx OR oropharyngeal OR "head and neck" OR nose OR nasopharynx OR "nasal sinus" OR "nasal cavity" OR "oral cavity" OR hypopharynx OR oral OR laryngopharynx OR larynx OR laryngopharyngeal OR laryngeal $\mathrm{OR}$ pharyngeal $\mathrm{OR}$ tonsil $\mathrm{OR}$ tonsillar $\mathrm{OR}$ tongue OR cheek OR palatal OR "paranasal sinuses" OR buccal OR lip) AND (microRNA OR miRNA OR "miR" OR "miRNA"). The inclusion criteria for the microarray datasets were as follows: (1) comprising data from HNSCC and noncancerous tissues; (2) evaluation of the association between miR-221-3p expression and clinical outcomes; and (3) availability of sufficient data to calculate the mean, SD and 95\% CI. The exclusion criteria were as follows: (1) unrelated to this study; (2) unqualified data; and (3) publication language other than English.

\section{A}

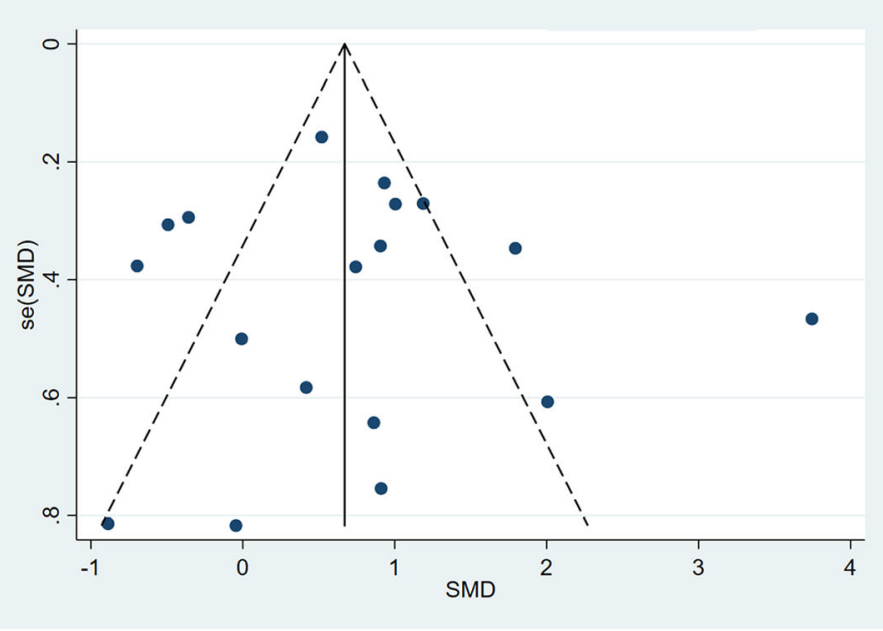

B

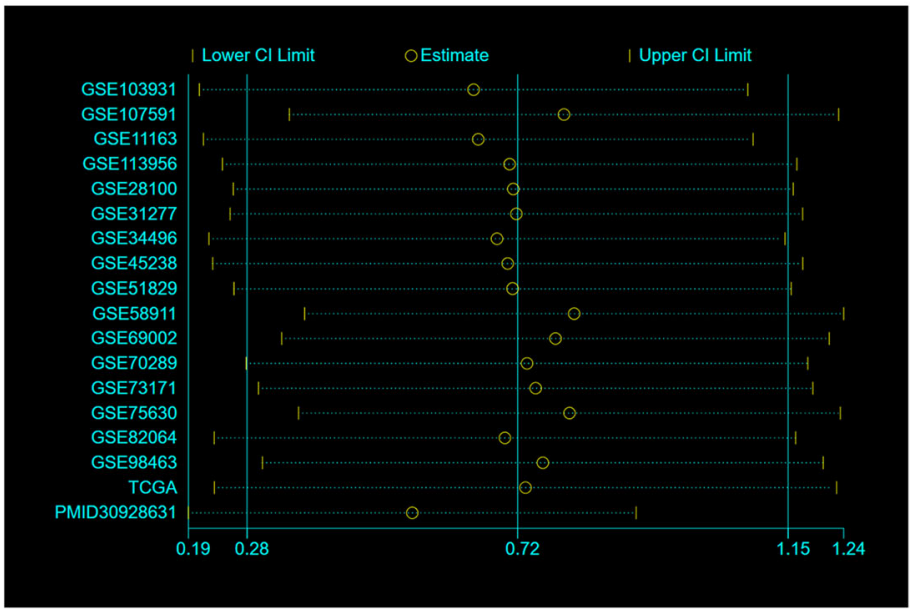

Fig. 3 Bias analysis. a Funnel plots of published data bias for meta-analysis of miR-21. b Sensitivity analysis for meta-analysis of miR-221-3p 
RNA sequencing data selection from TCGA

The miR-221-3p expression data of HNSCC and normal tissues and the clinicopathological parameters of patients were downloaded and extracted from the OncoLnc website (http://www.oncolnc.org/).

\section{Predicting the target genes of miR-221-3p in HNSCC}

We use the MiRWalk 2.0 [27] (http://zmf.umm. uniheidelberg.de/apps/zmf/mirwalk2/) and GEPIA (http://gepia.cancer-pku.cn/index.html) databases to retrieve differentially expressed genes of miR-221-3p in HNSCC. Gene Ontology (GO) [28] analysis, which was used to define the biological processes (BPs), molecular functions (MFs), and cellular components (CCs) of the target genes, and Kyoto Encyclopedia of Genes and Genomes (KEGG) [29] pathway enrichment analyses were conducted using R (version 3.6.1), and the ClusterProfiler package of $\mathrm{R}$ was used to visualize the results. The Search Tool for the Retrieval of Interacting Genes (STRI NG) (https://string-db.org/) was then used to establish a protein-protein interaction (PPI) network of the miR221-3p target genes associated with the significantly enriched pathways. The expression levels of the miR221-3p target genes in HNSCC and nontumor tissues were determined with UALCOULD [30] (http://ualcan. path.uab.edu/index.html). Finally, the LinkedOmics [31] (http://www.linkedomics.org/) Spearman's analysis tool was applied to determine the correlation between the expression levels of miR-221-3p and the potential target genes involved in notable signaling pathways.

\section{Statistical analysis}

Independent-Samples $\mathrm{T}$ Test for the RT-qPCR analysis of two groups. SPSS 24.0 software (IBM, Somers, NY) was used for the statistical analysis. The mean $\pm \mathrm{SD}(\mathrm{X} \pm$ s) were calculated, and t test was used for comparisons between groups for all the measurement data. Data that were used for our meta-analysis as well as TCGA data (Nanning, Guangxi Zhuang Autonomous Region, China) were analyzed using STATA 15.0 software. The standard mean difference (SMD) and 95\% confidence interval were used to estimate the expression value of miR-2213 p. Scatter plots of the data of both the normal and HNSCC tissues were prepared with GraphPad Prism 6 (Nanning, Guangxi Zhuang Autonomous Region, China) and used to assess the expression level of miR-221-3p. Evidence of bias was assessed by visual funnel plots and Egger's regression asymmetry test. In addition, the $\mathrm{I}^{2}$ index was used to evaluate the potential heterogeneity of the selected data. When $\mathrm{I}^{2}>50 \%$ or $P<0.05$, we used the fixed effect model; otherwise, the random effect model was used.. The count rate was expressed as a percentage (\%), and we used the $\mathrm{X}^{2}$ test for comparisons. The rates of true positives (TPs), false positives (FPs),

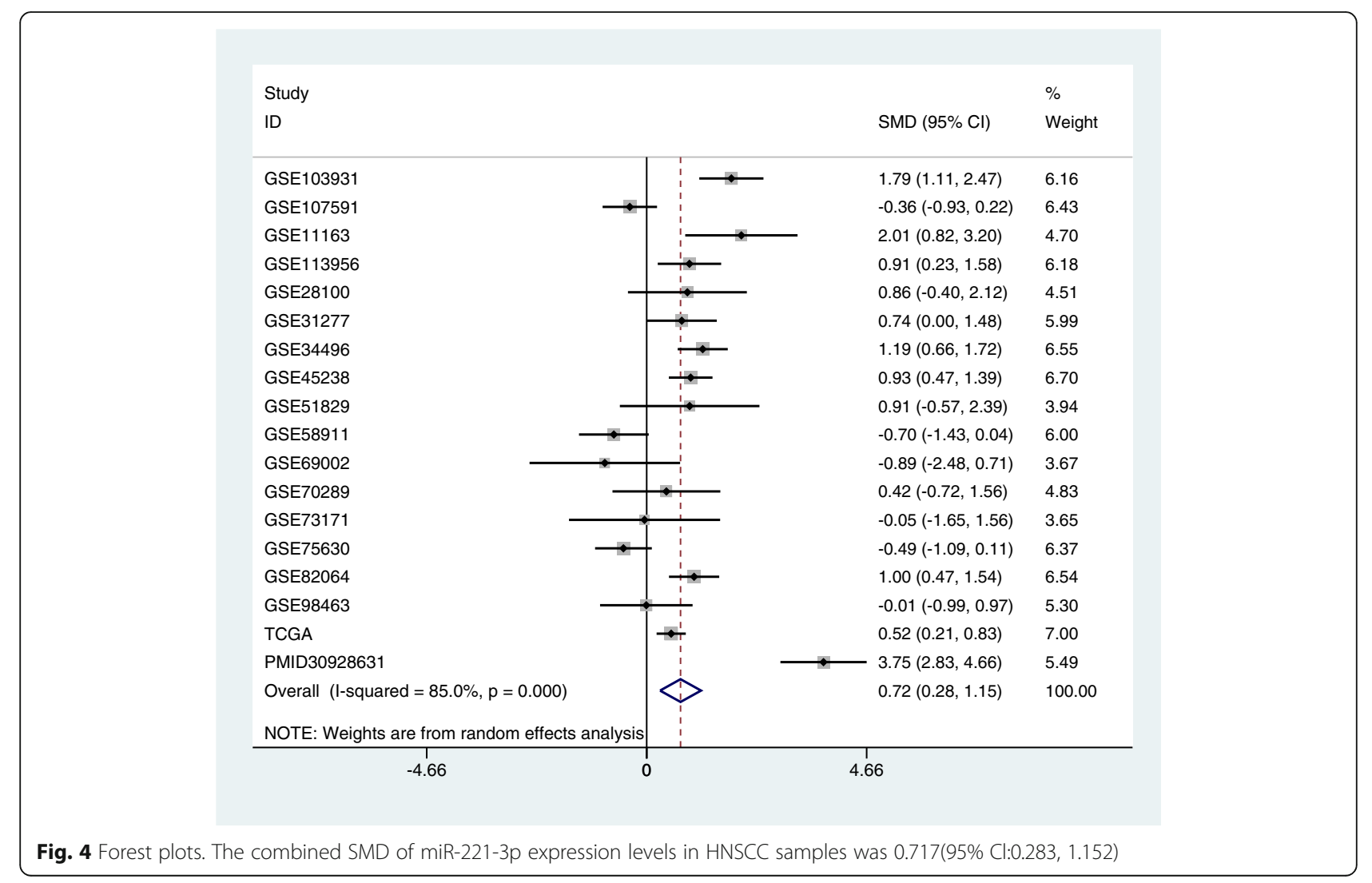


A

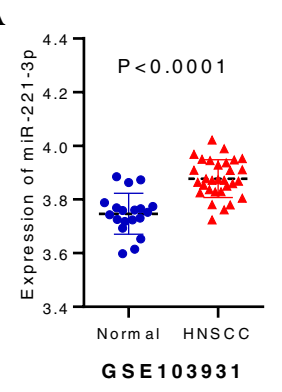

E

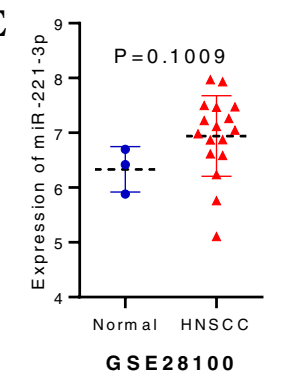

I

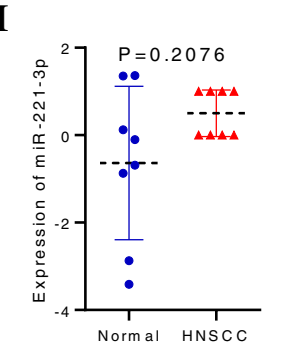

GSE51829

M

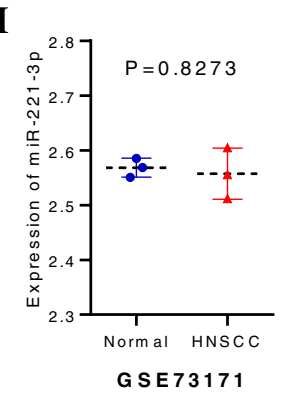

$\mathbf{Q}$

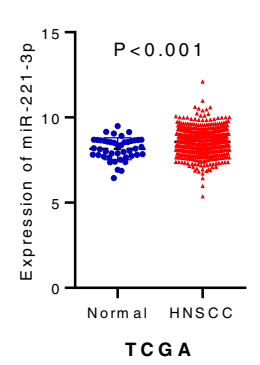

B

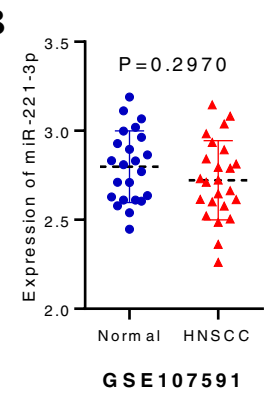

F

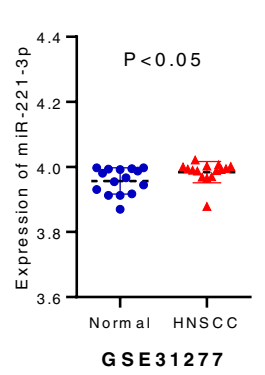

G

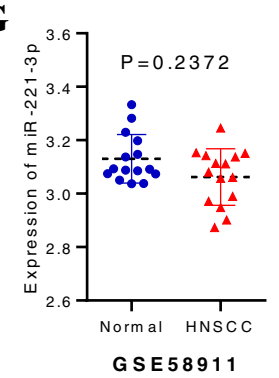

$\mathbf{N}$

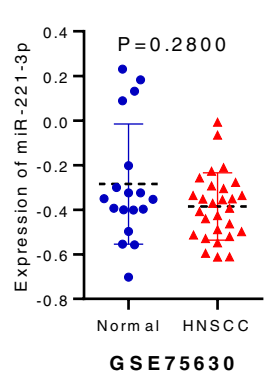

$\mathbf{R}$

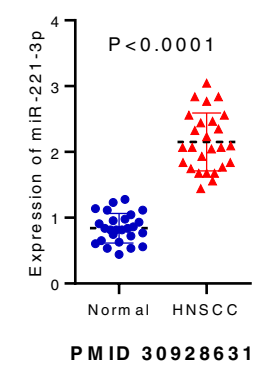

C

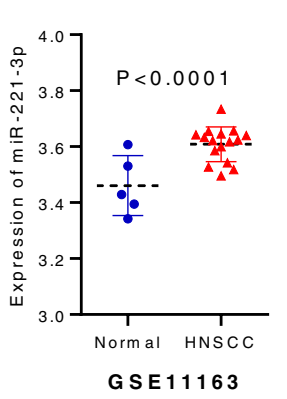

G

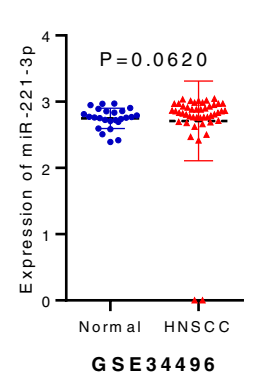

K

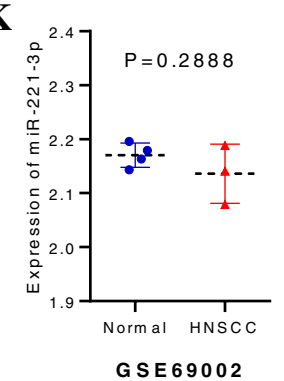

O

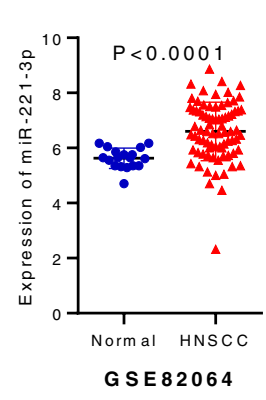

D

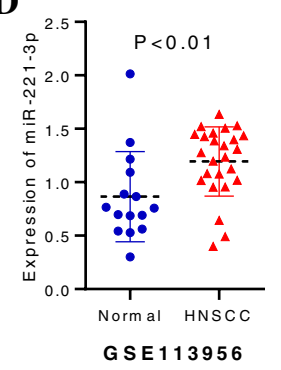

H

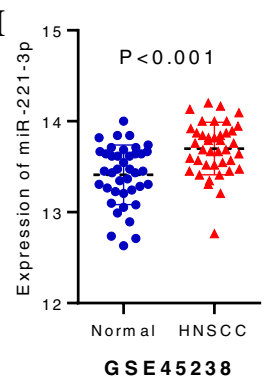

L

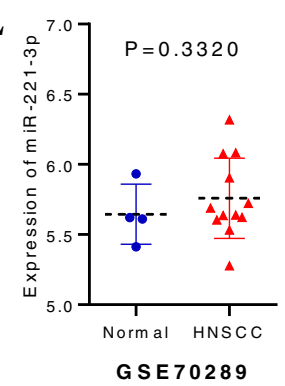

$\mathbf{P}$

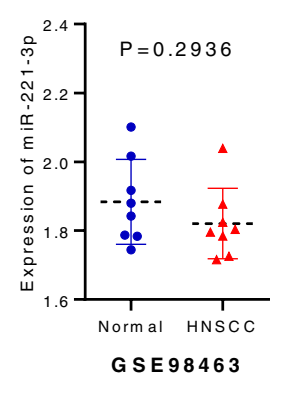

Fig. 5 The expression data of miR-221-3p in HNSCC from TCGA, each included GEO and the literature 
false negatives (FNs) and true negatives (TNs) were used to determine the diagnostic value of miR-221-3p. We used Meta-disc software to calculate the specificity, sensitivity, negative and positive likelihood ratios, and summary receiver operating characteristic (sROC) curve. We also performed sensitivity analysis to assess the differences between the sample sizes. Moreover, all the miR221-3p expression data, which included the TCGA sequencing data, were normalized to $\log 2$ to improve the normality of the measurements. $P<0.05$ was taken as a statistically significant difference for all analyses.

\section{Result}

\section{miR-221-3p is highly expressed in the tumor tissues}

The RT-qPCR data clearly showed that miR-221-3p is highly expressed in the tissues of nasopharyngeal carcinoma patients compared to the controls $(p<0.05)$ (Fig.1).

\section{Selection of relevant literature and microarray data extraction}

A total of 17 articles were retrieved from the initial search, and the following paper was selected after the full-text review based on the inclusion criteria: Zhou Cheng. et al. (PMID:30928631) [32] (Fig.2). Sixteen out of 424 GEO microarray datasets, including GSE11163, GSE103931, GSE107591, GSE113956, GSE28100, GSE31277, GSE34496, GSE45238, GSE51829, GSE58911, GSE69002, GSE70289, GSE73171, GSE75630, GSE82064, and GSE98463, met our inclusion criteria. Information for each included dataset is summarized in Table 1.

Risk of bias assessment and meta-analysis of miR-221$3 p$ in HNSCThe results of the visual funnel plots show a symmetrical shape, which indicates the absence of any significant publication bias as a whole. Sensitivity analysis performed to assess the heterogeneity of the samples showed that there were no significant differences between the studies (Fig.3). There were 911 HNSCC samples and 289 normal samples from the PubMed, GEO, and TCGA datasets. The meta-analysis performed on all data to explore the expression level of miR-221-3p in HNSCC indicated a high degree of heterogeneity between these studies. Therefore, the random-effects model was selected, and the combined standard mean difference (SMD) was observed to be 0.72 (95\% CI: 0.28, 1.15) (Fig.4). The meta-analysis data indicate that miR221-3p expression is significantly upregulated in HNSC $\mathrm{C}$, which is consistent with the results obtained by RTqPCR. In addition, miR-221-3p expression was significantly increased in HNSCC in the GSE11163, GSE103931, GSE113956, GSE31277, GSE45238, GSE82064, TCGA and PMID30928631 datasets, and the expression levels of miR-221-3p in HNSCC and normal tissues from each included dataset are shown in Fig.5.
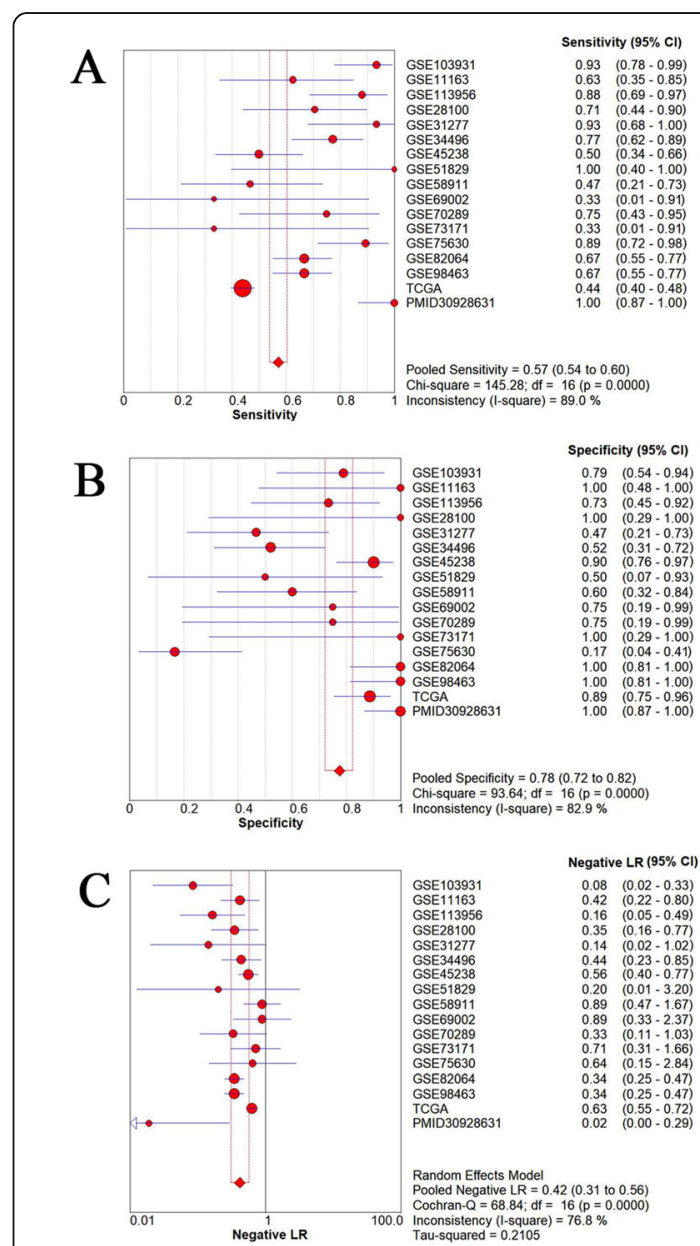

D
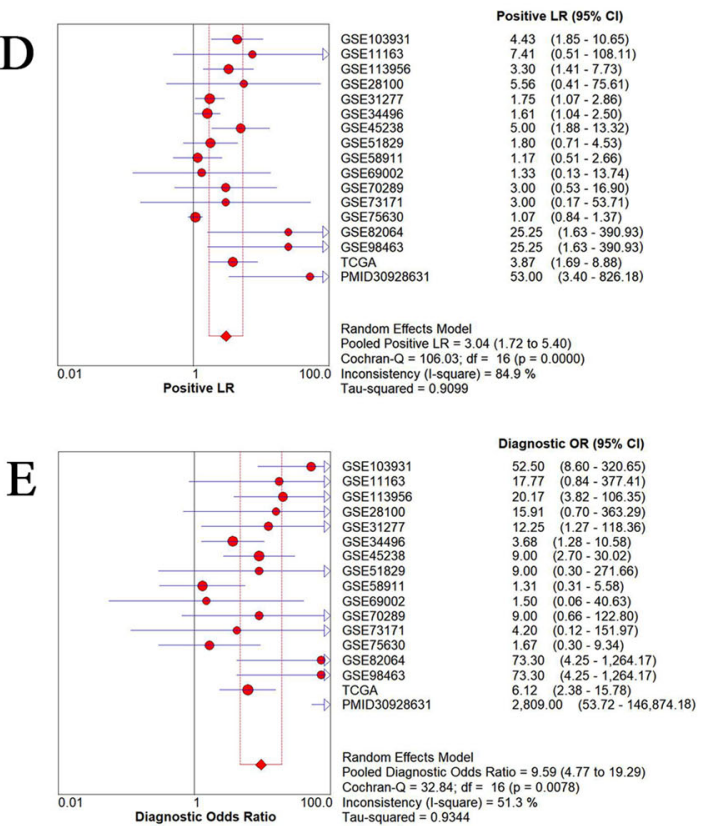

Fig. 6 The diagnostic value of miR-221-3p in HNSCC. a Sensitivity; (b) Specificity; (c) Negative LR; (d) Positive LR; (e) Diagnostic odds ratio 


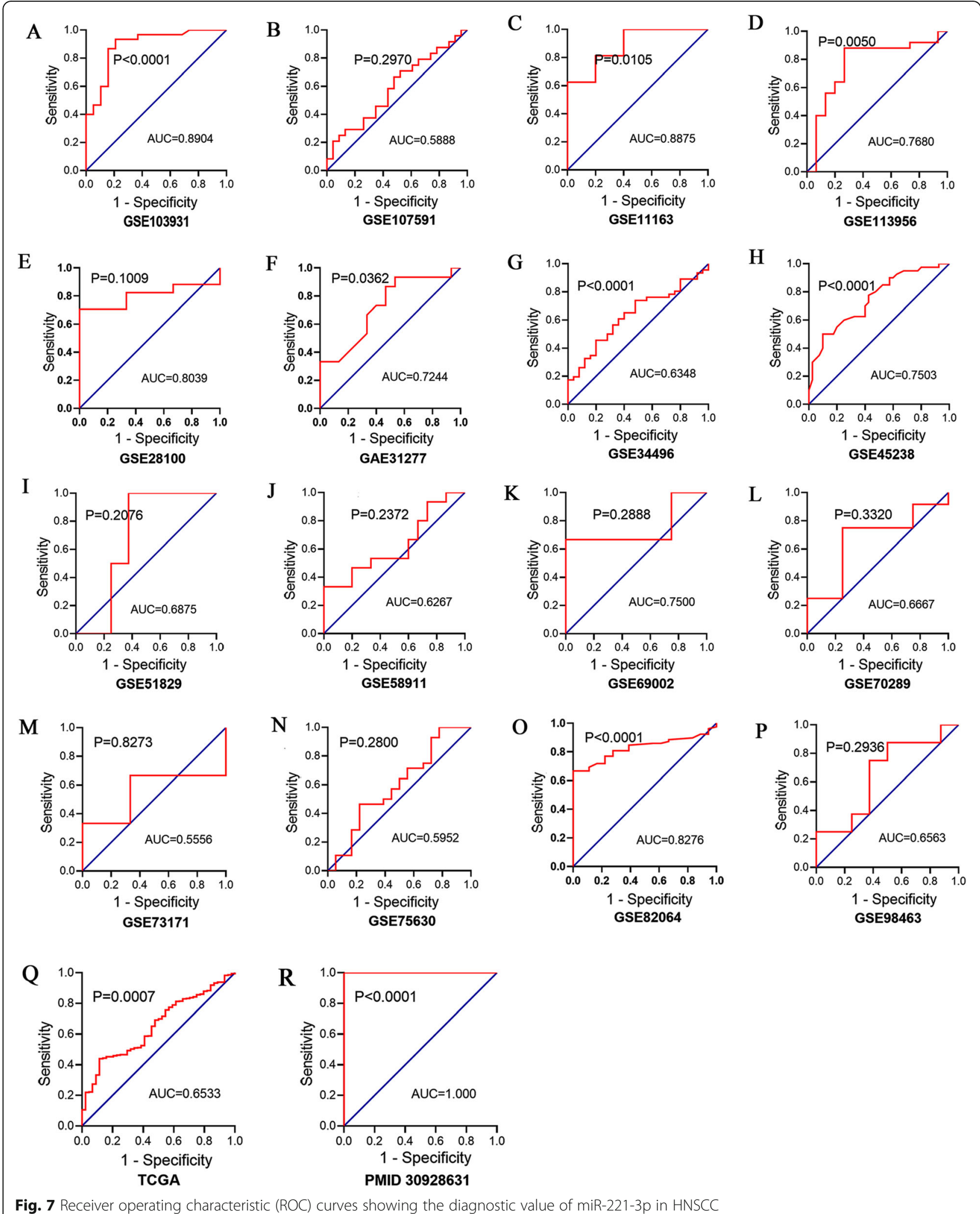

Fig. 7 Receiver operating characteristic (ROC) curves showing the diagnostic value of miR-221-3p in HNSCC 


\section{Diagnostic value of miR-221-3p in HNSCC}

The random-effects model used to analyze the diagnostic value of miR-221-3p for HNSCC showed significant heterogeneity in the likelihood ratio (negative and positive) sensitivity and specificity analyses. The diagnostic meta-analysis results indicated that the pooled specificity, sensitivity, likelihood ratio (negative and positive) and diagnostic odds ratio were 0.78 (95\% CI: 0.72-0.82), 0.57 (95\% CI: 0.54-0.60), 0.42 (95\% CI: $0.31-0.56)$ and 3.04 (95\% CI: 1.72-5.40), 9.59(95\% CI: 4.77-19.29) respectively (Fig.6). The receiver operating characteristic (ROC) curve of GSE103931, GSE11163, GSE113956, GSE31277, GSE34496, GSE45238, GSE82064, TCGA and PMID30928631 is statistically significant $(p<0.05$, Fig.7). Based on the ROC curve of each study, the overall ROC curve indicated that the area under the sROC curve (AUC) was $0.86(95 \% \mathrm{Cl}: 0.83,0.89)$ (Fig.8).

\section{Clinical features of HNSCC based on the TCGA}

Based on the HNSCC sample data extracted from the TCGA database, we analyzed 527 samples, and the results indicated the absence of any statistically significant difference between miR-221-3p expression and age, lymphatic invasion, neoplasm histologic grade and any other clinicopathological features. However, the results indicated statistically significant differences in the expression of miR-221-3p in different tissues, sexes, and even alcohol consumption statuses (Table 2).

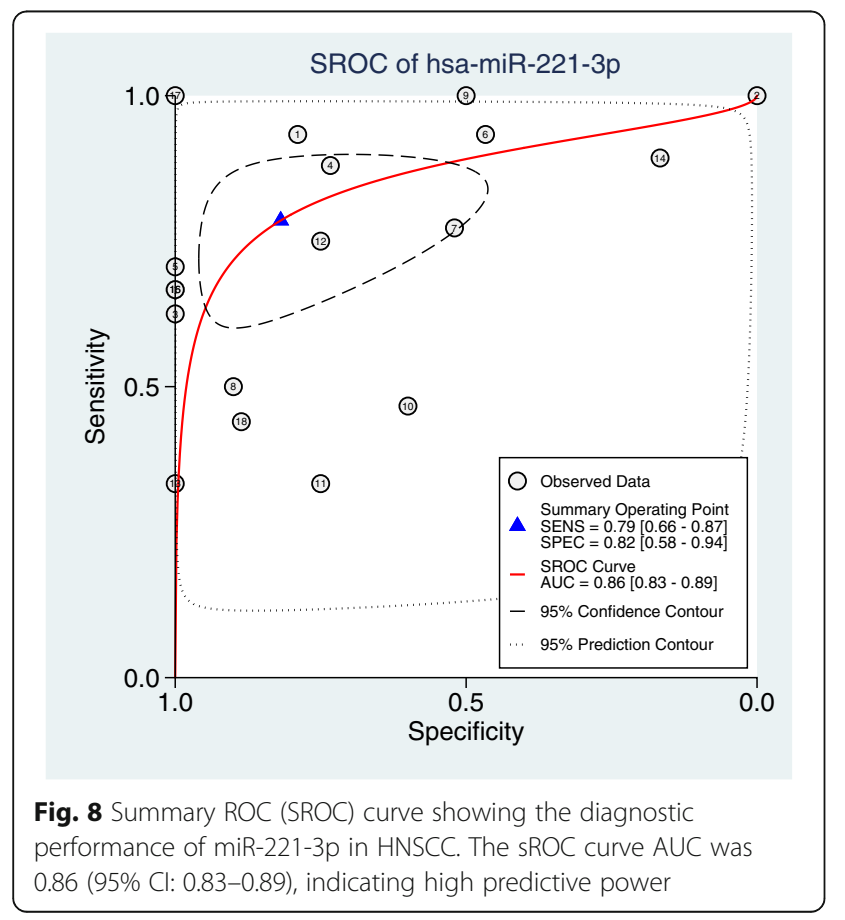

Table 2 The correlation between miR-221-3p expression levels and clinic characteristics based on TCGA database

\begin{tabular}{lllll}
\hline Clinicopathological features & Terms & $\mathbf{n}$ & Mean \pm SD & $\boldsymbol{p}$-value \\
\hline Unpaired tissue & Normal & 44 & $8.16 \pm 0.64$ & 0.001 \\
& HNSCC & 480 & $8.55 \pm 0.78$ & \\
Sex & Male & 383 & $8.45 \pm 0.79$ & 0.001 \\
& Female & 141 & $8.71 \pm 0.68$ & \\
Age & $<60$ & 234 & $8.50 \pm 0.76$ & 0.559 \\
& $>=60$ & 290 & $8.54 \pm 0.78$ & \\
lymphovascular invasion & NO & 232 & $8.54 \pm 0.81$ & 0.429 \\
& YES & 292 & $8.49 \pm 0.75$ & \\
Neoplasm histologic grade & G1-G2 & 371 & $8.49 \pm 0.73$ & 0.260 \\
& G3-G4 & 156 & $8.58 \pm 0.82$ & \\
M stage & MO & 498 & $8.51 \pm 0.78$ & 0.967 \\
& M1 & 29 & $8.51 \pm 0.57$ & \\
N stage & No & 246 & $8.53 \pm 0.76$ & 0.572 \\
Alcohol & N1-N3 & 281 & $8.49 \pm 0.77$ & \\
& NO & 164 & $8.62 \pm 0.76$ & 0.047 \\
HPV status & YES & 363 & $8.48 \pm 0.76$ & \\
Perineural invasion & Negative & 194 & $8.41 \pm 0.81$ & 0.066 \\
& Positive & 330 & $8.55 \pm 0.81$ & \\
\hline & NO & 198 & $8.53 \pm 0.81$ & 0.693 \\
& YES & 329 & $8.50 \pm 0.80$ & \\
\hline
\end{tabular}

Notes: HNSCC, Head and neck squamous cell carcinoma; T stage, size or direct extent of the primary tumor; $\mathrm{N}$ stage, degree of spread to regional lymph nodes; $\mathrm{M}$ stage, presence of distant metastasis; SD, standard deviation

The prospective target genes of miR-221-3p in HNSCC By using the MiRWalk 2.0 and GEPIA databases, we retrieved 5311 and 467 differentially expressed genes, respectively. Bioinformatics analysis showed a total of 117 overlapping genes that were involved (Fig.9, Table 3). These overlapped 117 genes could be considered as the target genes that miR-221-3p might play a role in HNSC C. The enriched GO and KEGG pathway categories of

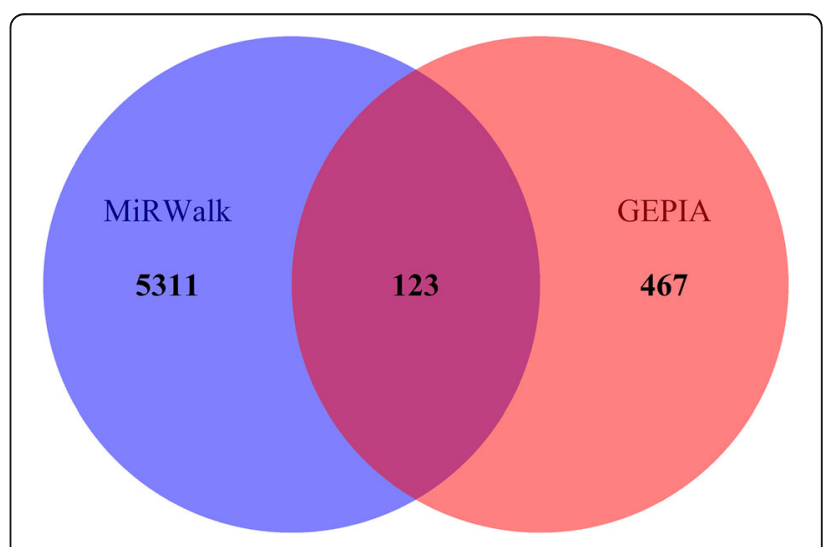

Fig. 9 Venn diagram showing overlapping miR-221-3p target genes 
Table 3 The promising target genes of miR-221-3p in HNSCC with TCGA and MiRWalk

\begin{tabular}{ll}
\hline $\begin{array}{l}\text { Sources of } \\
\text { genes }\end{array}$ & Genes \\
\hline TCGA and & AADAC, ACPP, ADH1B, ADH1C, ALDH1A1, AMOT, ANKRD35, ANXA1, AQP3, ASB5, ATP2A1, BCAS1, C2Orf54, C7, CA3, CAB39L, \\
MiRWalk & CAPN14, CAPN5, CAPN6, CD24, CEACAM6, CEACAM7, CGNL1, CHRDL1, CLU, COBL, CP, CRISP3, CRYM, CXCL17, CXCR2, CYP2F1, \\
& CYP3A5, CYP4B1, CYP4X1, DEPTOR, EHF, EIF1AY, EMP1, ENDOU, FAM189A2,FAM3D, FMO2, FOXA1, FUT3, GABRP, GATM, GBP6, \\
& GCNT3, GGT6, GPD1, GPT2, GPX3, GSTA1, HLF, HMGCS2, HPGD, HSPB8, IL1RN, KALRN, KLHL41, KRT23, KRT78, LDB3, LYNX1, MANSC1, \\
& MAOB, MAPT, MB, METL7A, MGLL, MUC21, MUC4, MYL2, MYZAP, NCCRP1, NDRG2, NFIX, PADI1, PADI2, PAX9, PCP4L1, PDK4, \\
& PEBP4, PI16, PLEKHA6, PPP1R1A, PPP1R3C, PSCA, PTN, RAET1E, RNF222, RRAGD, SCIN, SELENBP1, SERPINB13, SFRP1, SH3BGRL2, \\
& SLC16A7, SLC5A1, SMPX, SORBS1, SORBS2, STEAP4, SYNPO2, THSD4, TMEM45B, TNNI1, TPRG1, TRDN, TTC9, UGT1A7, UPK1A, \\
& VSIG10L, XIRP2, ZBTB7C, ZSCAN18
\end{tabular}

Notes: HNSCC: Head and neck squamous cell carcinoma; TCGA: The Cancer Genome Atlas

the overlapped 117 genes with $p<0.05$ are shown in Fig.10, Table 4 and Table 5. For the cellular components, the identified target genes were mostly enriched in the actin cytoskeleton, sarcomeres, and contractile fiber part; for the molecular functions, the target genes were mainly enriched in aromatase activity, oxidoreductase activity, and cofactor binding. KEGG enrichment analysis showed that miR-221-3p plays a significant role in HNSCC through a variety of pathways, including the drug metabolism pathways of the cytochrome P450 signaling pathway. The drug metabolism-cytochrome P450related genes include GSTA1, UGT1A7, CYP3A5, FMO2, MAOB, ADH1C and ADH1B, and the protein- protein interaction (PPI) network of these genes is shown in Fig.11.

\section{Validation of the miR-221-3p target genes in the drug metabolism-cytochrome P450 signaling pathway}

The expression values of each target gene are shown in Fig. 12, from which we learned that the 5 target genes (UGT1A7, CYP3A5, FMO2, MAOB and ADH1B) related to miR-221-3p were downregulated in the drug metabolism-cytochrome P450 pathway $(p<0.05)$. Spearman correlation analysis showed that GSTA1, UGT1A7 and MAOB, the target genes of the drug metabolism-

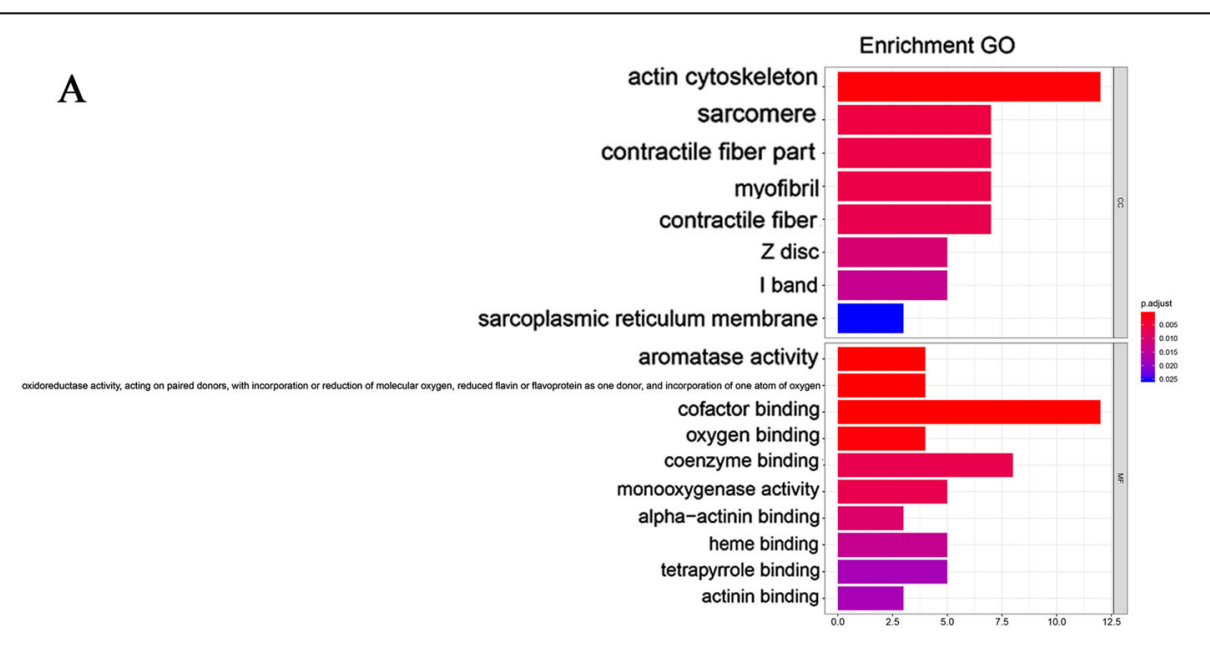

B KEGG pathway

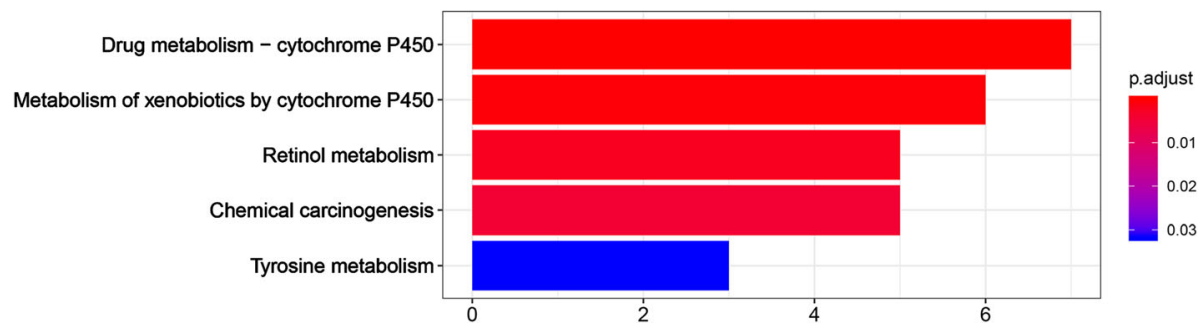

Fig. 10 Enrichment analysis of GO and KEGG pathways of miR-221-3p target genes. a Gene ontology (GO) of candidate genes; (b) Kyoto Encyclopedia of Genes and Genomes (KEGG) analysis 
Table 4 Predictive target genes of miR-221-3p with $\mathrm{GO}$ analysis

\begin{tabular}{|c|c|c|c|c|}
\hline GO ID & GO term & Count (\%) & Gene symbol & $p$-value \\
\hline \multicolumn{5}{|c|}{ Cellular component } \\
\hline GO:0015629 & actin cytoskeleton & 12 & $\begin{array}{l}\text { AMOT, ANXA1, CGNL1, COBL, KALRN, MYL2,MYZAP, } \\
\text { SCIN, SORBS1, SORBS2, SYNPO2, XIRP2 }\end{array}$ & $6.22 \mathrm{E}-06$ \\
\hline GO:0030017 & sarcomere & 7 & KLHL41, LDB3, MYL2, MYZAP, SORBS2, SYNPO2, XIRP2 & $6.06 \mathrm{E}-05$ \\
\hline GO:0044449 & contractile fiber part & 7 & KLHL41, LDB3, MYL2, MYZAP, SORBS2, SYNPO2, XIRP2 & 1.12E-04 \\
\hline GO:0030016 & myofibril & 7 & KLHL41, LDB3, MYL2, MYZAP, SORBS2, SYNPO2, XIRP2 & $1.32 \mathrm{E}-04$ \\
\hline GO:0043292 & contractile fiber & 7 & KLHL41, LDB3, MYL2, MYZAP, SORBS2, SYNPO2, XIRP2 & $1.90 \mathrm{E}-04$ \\
\hline GO:0030018 & Z disc & 5 & LDB3, MYZAP, SORBS2, SYNPO2, XIRP2 & 3.44E-04 \\
\hline GO:0031674 & I band & 5 & LDB3, MYZAP, SORBS2, SYNPO2, XIRP2 & $5.21 \mathrm{E}-04$ \\
\hline GO:0033017 & sarcoplasmic reticulum membrane & 3 & ATP2A1, KLHL41, TRDN & $1.11 \mathrm{E}-03$ \\
\hline \multicolumn{5}{|c|}{ Molecular function } \\
\hline GO:0070330 & aromatase activity & 4 & CYP2F1, CYP3A5, CYP4B1, CYP4X1 & $6.04 \mathrm{E}-06$ \\
\hline GO:0016712 & $\begin{array}{l}\text { oxidoreductase activity, acting on paired donors, } \\
\text { with incorporation or reduction of molecular oxygen, } \\
\text { reduced flavin or flavoprotein as one donor, } \\
\text { and incorporation of one atom of oxygen }\end{array}$ & 4 & CYP2F1, CYP3A5, CYP4B1, CYP4X1 & 8.86E-06 \\
\hline GO:0048037 & cofactor binding & 12 & $\begin{array}{l}\text { ALDH1A1, CRYM, CYP3A5, CYP4B1, CYP4X1, FMO2, } \\
\text { GPD1, GPT2, HPGD, MAOB, MB, STEAP4 }\end{array}$ & $9.13 \mathrm{E}-06$ \\
\hline GO:0019825 & oxygen binding & 4 & CYP2F1, CYP3A5, CYP4B1, MB & 1.73E-05 \\
\hline GO:0050662 & coenzyme binding & 8 & $\begin{array}{l}\text { ALDH1A1, CRYM, FMO2, GPD1, GPT2, HPGD, MAOB, } \\
\text { STEAP4 }\end{array}$ & 1.30E-04 \\
\hline GO:0004497 & monooxygenase activity & 5 & CYP2F1, CYP3A5, CYP4B1, CYP4X1, FMO2 & 1.46E-04 \\
\hline GO:0051393 & alpha-actinin binding & 3 & LDB3, SYNPO2, XIRP2 & 2.37E-04 \\
\hline GO:0020037 & heme binding & 5 & CYP3A5, CYP4B1, CYP4X1, MB, STEAP4 & $3.88 \mathrm{E}-04$ \\
\hline GO:0046906 & tetrapyrrole binding & 5 & CYP3A5, CYP4B1, CYP4X1, MB, STEAP4 & 5.87E-04 \\
\hline GO:0042805 & actinin binding & 3 & LDB3, SYNPO2, XIRP2 & 6.30E-04 \\
\hline GO:0016705 & $\begin{array}{l}\text { oxidoreductase activity, acting on paired donors, } \\
\text { with incorporation or reduction of molecular oxygen }\end{array}$ & 5 & CYP2F1, CYP3A5, CYP4B1, CYP4X1, FMO2 & $1.24 \mathrm{E}-03$ \\
\hline GO:0033130 & acetylcholine receptor binding & 2 & LYNX1, PSCA & 1.47E-03 \\
\hline GO:0016722 & oxidoreductase activity, oxidizing metal ions & 2 & CP, STEAP4 & $2.14 \mathrm{E}-03$ \\
\hline GO:0030674 & protein binding, bridging & 5 & MAPT, SORBS1, SORBS2, SYNPO2, TRDN & 2.20E-03 \\
\hline
\end{tabular}

Notes: GO: Gene Ontology

cytochrome $\mathrm{P} 450$, were correlated with miR-221-3p in HNSCC ( $<<0.05$, Fig.13).

\section{Discussion}

The drug metabolism-cytochrome P450 signaling pathway is an essential signal transduction pathway in cells. It is an important biological function of cell survival, proliferation and apoptosis. For example, Liping Wang and his colleagues suggest [33] that the inhibition of CYP3A5 in cytochrome P450 drug metabolism can drive the migration, proliferation, and invasion of HNSCC cells. Dongfang Wang et al. showed that cytochrome P450 is correlated with the overall survival and vascular invasion of hepatocellular carcinoma (HCC) patients.

Table 5 KEGG pathway of validated target genes of miR-221-3p

\begin{tabular}{llll}
\hline KEGG ID & KEGG term & Count (\%) & Gene symbol \\
\hline hsa00982 & Drug metabolism - cytochrome P450 & 7 & GSTA1, UGT1A7, CYP3A5, FMO2, MAOB, ADH1C, ADH1B \\
hsa00980 & Metabolism of xenobiotics by cytochrome P450 & 6 & GSTA1, UGT1A7, CYP3A5, CYP2F1, ADH1C, ADH1B \\
hsa00830 & Retinol metabolism & 5 & UGT1A, ALDH1A1, CYP3A5, ADH1C, ADH1B \\
hsa05204 & Chemical carcinogenesis & 5 & GSTA1, UGT1A7, CYP3A5, ADH1C, ADH1B \\
hsa00350 & Tyrosine metabolism & 3 & MAOB, ADH1C, ADH1B \\
\hline
\end{tabular}

Notes: KEGG: Kyoto Encyclopedia of Genes and Genomes 


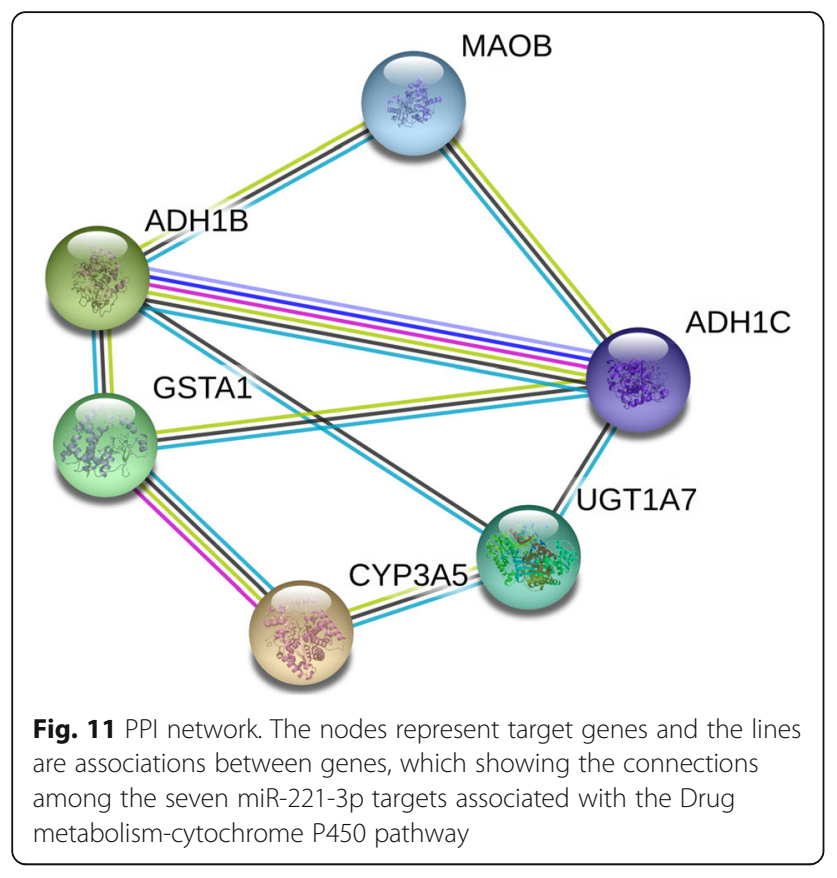

Additionally, inhibiting the P450 pathway in drug metabolism-cytochrome can increase the efficacy of HNSCC [34]. Among the target genes of miR-221-3p, MAOB and UGT1A7 are associated with the miR-221$3 \mathrm{p}$ and drug-cytochrome $\mathrm{P} 450$ signaling pathway and are downregulated in HNSCC $(\mathrm{p}<0.05)$. MAOB is regarded as a novel biomarker for accurate prostate cancer diagnosis and treatment [35]. In addition, a large number of valuable epidemiological studies have shown that UGT1A7 affects individuals' susceptibility to various cancers, such as pancreatic cancer [36] and gastrointestinal carcinomas [37]. Our study suggests that miR-221$3 p$ may play an important role as a gene that promotes the development of HNSCC by reducing the expression of the MAOB and UGT1A7 pathways in HNSCC.

Understanding the pathogenesis of HNSCC and identifying new gene therapy programs have been the focus of recent studies. Many recent studies have reported that miRNAs with different expression patterns in different tumors [38-42] control the progression of tumors. For example, miR-221-3p has been regarded as a tumor biomarker that can be used to assess the clinical prognosis

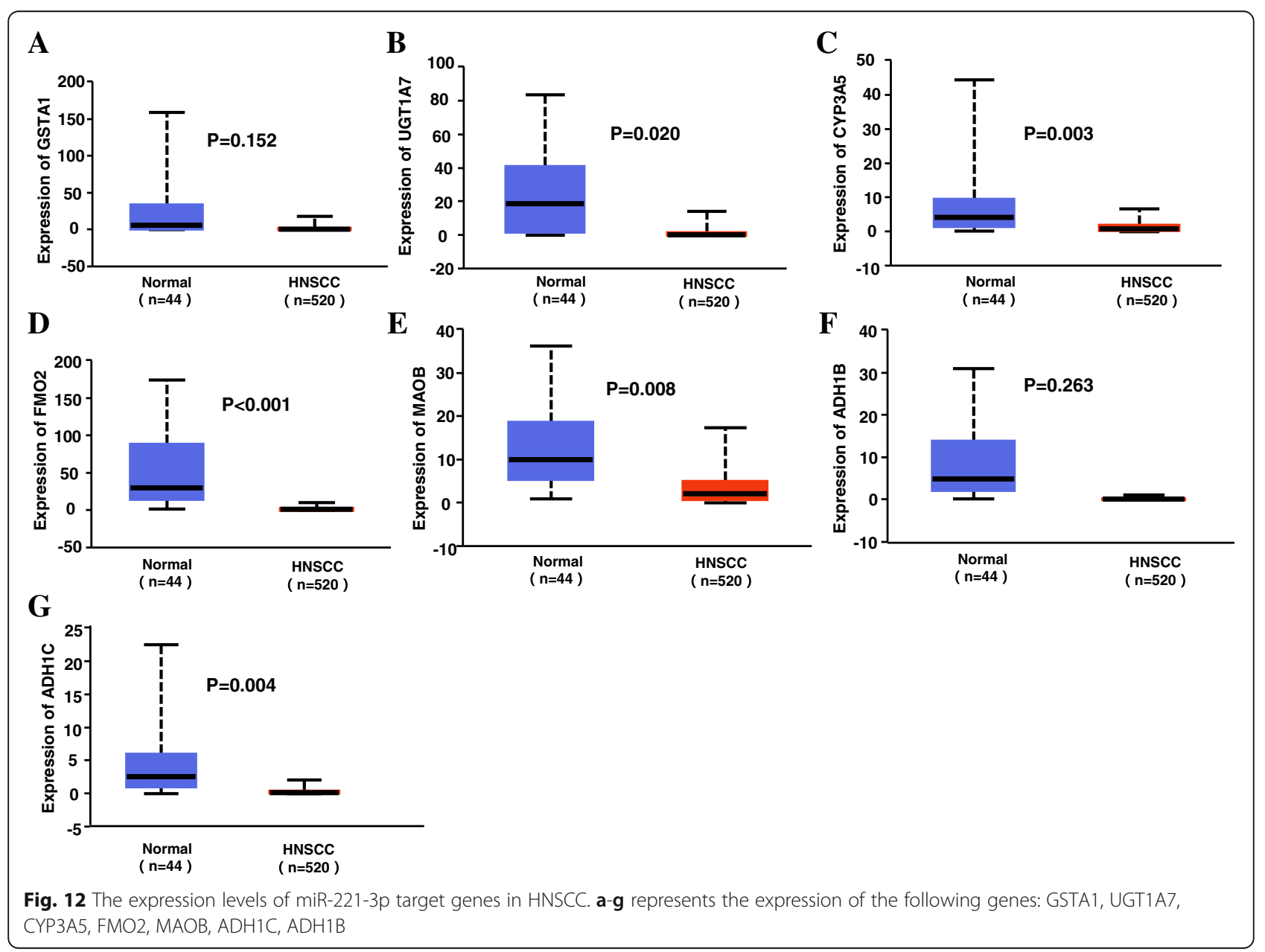




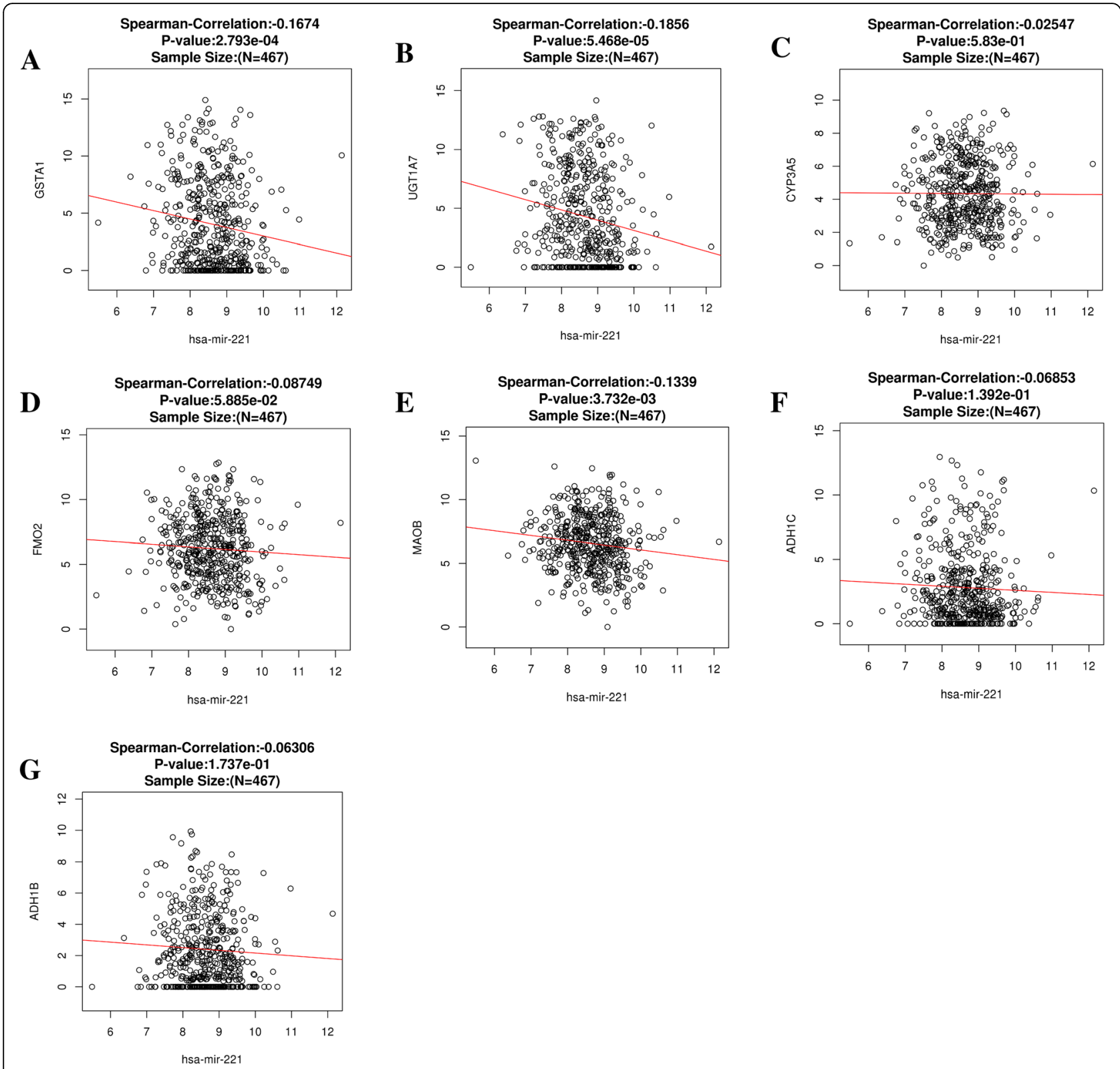

Fig. 13 Spearman analysis. a-g show the association between miR-221-3p expression levels and the seven identified target genes involved in the Drug metabolism - cytochrome P450 pathway

of breast cancer [15]. In healthy humans, it has been shown that miR-221-3p plays a role in the process of vascular proliferation, while the tumor promoter miR221-3p regulates the apoptosis of tumor cells. The current study focused on the expression pattern of miR221-3p in HNSCC, identifying the exact target genes of this miRNA and its biological mechanism of action through bioinformatics analysis. The biological pathways relevant to the actions of miR-221-3p will guide further understanding of the mechanisms of HNSCC.
Of course, the limitations of our study should also be mentioned. On the one hand, this study is restricted in that the analysis of differential miRNAs was only based on HNSCC and noncancerous tissues, and other samples (e.g., blood) were not assessed. On the other hand, the target genes of miR-221-3p have not been experimentally confirmed, and our conclusions will need to be confirmed by clinical or molecular biological methods in the future. In addition, only English studies were used for the basis of our meta-analysis, which did not include 
other potentially relevant studies that were in other languages.

\section{Conclusion}

In our study, we found that miR-221-3p levels were apparently upregulated in HNSCC compared to normal tissues. MAOB and UGT1A7 are potentially important targets of miR-221-3p. MiR-221-3p may be used as a noninvasive and hypersensitive biomarker for the diagnosis of HNSCC and is an extremely important gene locus involved in the process of the deterioration and eventual tumorigenesis of HNSCC. Finally, the biological pathways relevant to the actions of miR-221-3p will provide insights into its potential molecular mechanisms in HNSCC. Larger-scale studies will be needed to validate its diagnostic promise. Hopefully, additional work will validate its usefulness as a target for future clinical research.

\section{Abbreviations}

HNSCC: Head and neck squamous cell carcinoma; miR: microRNA; PPI: protein-protein interaction; GO: Gene Ontology; KEGG: Kyoto Encyclopedia of Genes and Genomes; GEO: Gene Expression Omnibus; TCGA: The cancer genome atlas; DAVID: Database for Annotation, Visualization and Integrated Discovery; BiNGO: Biological Networks Gene Oncology tool; BP: biological process; CC: cellular component; MF: molecular function

\section{Acknowledgements}

Not applicable.

\section{Authors' contributions}

MK designed the study and accessed the relevant information, YZZ designed the study, analyzed data, and wrote the manuscript. And YZZ and LWW collected and analyzed and interpreted the data. XJL, XZX and CL were involved in statistical analysis. QQL, JMS, XRQ and SS critically revised the manuscript. All authors read and approved the final manuscript.

\section{Funding}

This work was supported by grants from the National Natural Science Foundation of China (No. 81460460,81760542), The Research Foundation of the Science and Technology Department of Guangxi Province, China (grant No. 2016GXNSFAA380252, 2018AB61001 and 2014GXNSFBA118114), the Research Foundation of the Health Department of Guangxi Province, China (No. S2018087). The funding body had no role in the design of the study and collection, analysis, and interpretation of data and in writing this manuscript.

\section{Availability of data and materials}

All data generated or analyzed during this study are included in this published article.

\section{Declarations}

\section{Ethics approval and consent to participate}

All procedures were approved by the Ethics Committee of Guangxi Medical University (Nanning, China). Written informed consent was obtained from all patients or their families prior to enrolment in the present study.

\section{Consent for publication}

Not applicable.

\section{Competing interests}

The authors declared that they have no competing interests.

\section{Author details}

'Department of Radiation Oncology, Guangxi Medical University First Affiliated Hospital, Nanning 530021, Guangxi, People's Republic of China. ${ }^{2}$ Guangxi Tumor Radiation Therapy Clinical Medical Research Center, Nanning 530021, Guangxi, People's Republic of China. ${ }^{3}$ Department of Medical Oncology, The First Affiliated Hospital of Guangxi Medical University, Nanning 530021, Guangxi, People's Republic of China. ${ }^{4}$ Guangxi Medical University, Nanning 530021, Guangxi, People's Republic of China.

${ }^{5}$ Department of Thoracic Surgery, The First Affiliated Hospital of Guangxi Medical University, Nanning, Guangxi Zhuang Autonomous Region, People's Republic of China.

Received: 3 November 2020 Accepted: 15 March 2021 Published online: 12 April 2021

\section{References}

1. Avissar M, Christensen BC, Kelsey KT, Marsit CJ. MicroRNA expression ratio is predictive of head and neck squamous cell carcinoma. Clin Cancer Res. 2009;15(8):2850-5. https://doi.org/10.1158/1078-0432.CCR-08-3131.

2. Allen B, Schneider A, Victoria B, Nunez Lopez YO, Muller M, Szewczyk M, Pazdrowski J, Majchrzak E, Barczak W, Golusinski W, Golusinski P, Masternak MM. Blood serum from head and neck squamous cell carcinoma patients induces altered MicroRNA and target gene expression profile in treated cells. Front Oncol. 2018:8:217. https://doi.org/10.3389/fonc.2018.00217.

3. Peitzsch C, Nathansen J, Schniewind SI, Schwarz F, Dubrovska A. Cancer stem cells in head and neck squamous cell carcinoma: identification, Characterization and Clinical Implications. Cancers. 2019;11(5):616.

4. Ausoni S, Boscolo-Rizzo P, Singh B, Da Mosto MC, Spinato G, Tirelli G, Spinato R, Azzarello G. Targeting cellular and molecular drivers of head and neck squamous cell carcinoma: current options and emerging perspectives. Cancer Metastasis Rev. 2016;35(3):413-26. https://doi.org/10.1007/s10555-01 6-9625-1.

5. Britt EL, Raman S, Leek K, Sheehy CH, Kim SW, Harada H. Combination of fenretinide and ABT-263 induces apoptosis through NOXA for head and neck squamous cell carcinoma treatment. PLoS One. 2019;14(7):e0219398. https://doi.org/10.1371/journal.pone.0219398.

6. Koole $\mathrm{K}$, Clausen MJ, van Es RJ, van Kempen PM, Melchers $L$, Koole R, Langendijk JA, van Diest PJ, Roodenburg JL, Schuuring E, et al. FGFR family members protein expression as prognostic markers in Oral cavity and Oropharyngeal squamous cell carcinoma. Molecular diagnosis therapy. 2016; 20(4):363-74. https://doi.org/10.1007/s40291-016-0204-5.

7. Tang XX, He J, Li B, Zheng Y, Li KJ, Zou S, Chen L. Efficacy and safety of Gefitinib in patients with advanced head and neck squamous cell carcinoma: a meta-analysis of randomized controlled trials. J Oncol. 2019; 2019:6273438.

8. Cao W, Liu J, Xia R, Lin L, Wang X, Xiao M, Zhang C, Li J, Ji T, Chen W. Xlinked FHL1 as a novel therapeutic target for head and neck squamous cell carcinoma. Oncotarget. 2016;7(12):14537-50. https://doi.org/10.18632/ oncotarget.7478.

9. Ahmad P, Sana J, Slavik M, Slampa P, Smilek P, Slaby O. MicroRNAs involvement in Radioresistance of head and neck Cancer. Dis Markers. 2017; 2017:8245345.

10. Orosz E, Gombos K, Riedling T, Afiakurue P, Kiss I, Pytel J, Gerlinger I, Szanyi I. Comparative miRNA expression profile analysis of squamous cell carcinoma and Peritumoral mucosa from the Meso- and Hypopharynx. Cancer Genomics Proteomics. 2017;14(4):285-92. https://doi.org/10.21873/ cgp.20039.

11. Qureshi R, Sacan A. A novel method for the normalization of microRNA RTPCR data. BMC Med Genomics. 2013;6(Suppl 1):S14.

12. Irani S. miRNAs signature in head and neck squamous cell carcinoma metastasis: a literature review. J Dent. 2016;17(2):71-83.

13. Wang $H$, Tang $Y$, Yang D, Zheng L. MicroRNA-591 functions as a tumor suppressor in hepatocellular carcinoma by lowering drug resistance through inhibition of far-upstream element-binding protein 2-mediated Phosphoinositide 3-kinase/Akt/mammalian target of Rapamycin Axis. Pharmacology. 2019:1-14.

14. Hussein S, Mosaad H, Rashed HE, El-Anwar MW. Up-regulated miR-221 expression as a molecular diagnostic marker in laryngeal squamous cell carcinoma and its correlation with Apaf-1 expression. Cancer Biomark. 2017; 19(3):279-87. https://doi.org/10.3233/CBM-160444. 
15. Zhou L, Jiang F, Chen X, Liu Z, Ouyang Y, Zhao W, Yu D. Downregulation of miR-221/222 by a microRNA sponge promotes apoptosis in oral squamous cell carcinoma cells through upregulation of PTEN. Oncol Lett. 2016;12(6): 4419-26. https://doi.org/10.3892/ol.2016.5250.

16. Deng X, Ma L, Wu M, Zhang G, Jin C, Guo Y, Liu R. miR-124 radiosensitizes human glioma cells by targeting CDK4. J Neurooncol. 2013;114(3):263-74. https://doi.org/10.1007/s11060-013-1179-2.

17. Rippe C, Blimline M, Magerko KA, Lawson BR, LaRocca TJ, Donato AJ, Seals DR. MicroRNA changes in human arterial endothelial cells with senescence: relation to apoptosis, eNOS and inflammation. Exp Gerontol. 2012:47(1):4551. https://doi.org/10.1016/j.exger.2011.10.004

18. Gillies JK, Lorimer IA. Regulation of p27Kip1 by miRNA 221/222 in glioblastoma. Cell Cycle. 2007;6(16):2005-9. https://doi.org/10.4161/cc.6.1 6.4526.

19. Felicetti F, Errico MC, Bottero L, Segnalini P, Stoppacciaro A, Biffoni M, Felli N, Mattia G, Petrini M, Colombo MP, Peschle C, Care A. The promyelocytic leukemia zinc finger-microRNA-221/-222 pathway controls melanoma progression through multiple oncogenic mechanisms. Cancer Res. 2008; 68(8):2745-54. https://doi.org/10.1158/0008-5472.CAN-07-2538.

20. Ambs S, Prueitt RL, Yi M, Hudson RS, Howe TM, Petrocca F, Wallace TA, Liu CG, Volinia S, Calin GA, Yfantis HG, Stephens RM, Croce CM. Genomic profiling of microRNA and messenger RNA reveals deregulated microRNA expression in prostate cancer. Cancer Res. 2008;68(15):6162-70. https://doi. org/10.1158/0008-5472.CAN-08-0144.

21. Li J, Wang Y, Yu W, Chen J, Luo J. Expression of serum miR-221 in human hepatocellular carcinoma and its prognostic significance. Biochem Biophys Res Commun. 2011;406(1):70-3. https://doi.org/10.1016/j.bbrc.2011.01.111.

22. Ergun S, Arman K, Temiz E, Bozgeyik I, Yumrutas O, Safdar M, Dagli H, Arslan A, Oztuzcu S. Expression patterns of miR-221 and its target Caspase-3 in different cancer cell lines. Mol Biol Rep. 2014;41(9):5877-81. https://doi.org/1 0.1007/s11033-014-3461-6.

23. Wald Al, Hoskins EE, Wells SI, Ferris RL, Khan SA. Alteration of microRNA profiles in squamous cell carcinoma of the head and neck cell lines by human papillomavirus. Head Neck. 2011;33(4):504-12. https://doi.org/10.1 002/hed.21475.

24. Yang CJ, Shen WG, Liu CJ, Chen YW, Lu HH, Tsai MM. Lin SC: miR-221 and miR-222 expression increased the growth and tumorigenesis of oral carcinoma cells. J Oral Pathol Med. 2011;40(7):560-6. https://doi.org/1 0.1111/j.1600-0714.2010.01005.x

25. Liu CJ, Kao SY, Tu HF, Tsai MM, Chang KW, Lin SC. Increase of microRNA miR-31 level in plasma could be a potential marker of oral cancer. Oral Dis. 2010;16(4):360-4. https://doi.org/10.1111/j.1601-0825.2009.01646.x.

26. Wong TS, Liu XB, Wong BY, Ng RW, Yuen AP, Wei WI. Mature miR-184 as potential oncogenic microRNA of squamous cell carcinoma of tongue. Clin Cancer Res. 2008;14(9):2588-92. https://doi.org/10.1158/1 078-0432.CCR-07-0666.

27. Dweep H. Gretz N: miRWalk2.0: a comprehensive atlas of microRNA-target interactions. Nat Methods. 2015;12(8):697.

28. Ashburner M, Ball CA, Blake JA, Botstein D, Butler H, Cherry JM, Davis AP, Dolinski K, Dwight SS, Eppig JT, Harris MA, Hill DP, Issel-Tarver L, Kasarskis A, Lewis S, Matese JC, Richardson JE, Ringwald M, Rubin GM, Sherlock G. Gene ontology: tool for the unification of biology. The gene ontology consortium. Nat Genet. 2000;25(1):25-9. https://doi.org/10.1038/75556.

29. Kanehisa M, Goto S, Sato Y, Furumichi M, Tanabe M. KEGG for integration and interpretation of large-scale molecular data sets. Nucleic Acids Res. 2012;40(Database issue):D109-14. https://doi.org/10.1093/nar/gkr988.

30. Chandrashekar DS, Bashel B, Balasubramanya SAH, Creighton CJ, Ponce-Rodriguez I, Chakravarthi B, Varambally S. UALCAN: A Portal for Facilitating Tumor Subgroup Gene Expression and Survival Analyses. Neoplasia. 2017;19(8):649-58.

31. Vasaikar SV, Straub P, Wang J, Zhang B. LinkedOmics: analyzing multi-omics data within and across 32 cancer types. Nucleic Acids Res. 2018;46(D1): D956-d963. https://doi.org/10.1093/nar/gkx1090.

32. Cheng Z, Xing D. Ginsenoside Rg3 inhibits growth and epithelialmesenchymal transition of human oral squamous carcinoma cells by downregulating miR-221. Eur J Pharmacol. 2019;853:353-63. https://doi.org/10.101 6/j.ejphar.2019.03.040.

33. Wang LP, Chen WH, Zha J, Yan YY, Wei YX, Chen XL, Zhu XX, Ge LH. miR543 acts as a novel oncogene in oral squamous cell carcinoma by targeting CYP3A5. Oncol Rep. 2019;42(3):973-90. https://doi.org/10.3892/or.2019.7230.

34. Ruwali M, Dhawan A, Pant MC, Rahman Q, Khurana SM, Parmar D. Clinical Management of Head and Neck Cancer Cases: role of Pharmacogenetics of
CYP2 and GSTs. Oncol Res Treat. 2016;39(4):221-6. https://doi.org/10.1159/ 000444608.

35. Xu N, Wu Y-P, Ke Z-B, Liang Y-C, Cai H, Su W-T, Tao X, Chen S-H, Zheng Q-S, Wei $Y$, et al. Identification of key DNA methylation-driven genes in prostate adenocarcinoma: an integrative analysis of TCGA methylation data. J Transl Med. 2019:17(1).

36. Yilmaz L, Borazan E, Aytekin T, Baskonus I, Aytekin A, Oztuzcu S, Bozdag Z, Balik A. Increased UGT1A3 and UGT1A7 expression is associated with pancreatic Cancer. Asian Pac J Cancer Prev. 2015;16(4):1651-5. https://doi. org/10.7314/APJCP.2015.16.4.1651.

37. Cengiz B, Yumrutas O, Bozgeyik E, Borazan E, Igci YZ, Bozgeyik I, Oztuzcu S. Differential expression of the UGT1A family of genes in stomach cancer tissues. Tumor Biol. 2015;36(8):5831-7. https://doi.org/10.1007/s13277-015-3253-1.

38. Chen W, Fu W, Deng Q, Li Y, Wang K, Bai Y, Wu X, Li G, Wang G, Huang J, He M, Zhang X, Wu T, Wei S, Guo H. Multiple metals exposure and chromosome damage: exploring the mediation effects of microRNAs and their potentials in lung carcinogenesis. Environ Int. 2019;122:291-300. https://doi.org/10.1016/j.envint.2018.11.020.

39. Dong XT, Liu YD. Expression and significance of miR-24 and miR-101 in patients with advanced gastric cancer. Oncol Lett. 2018;16(5):5769-74. https://doi.org/10.3892/ol.2018.9324.

40. Jin FF, Yang $R$, Wei Y, Wang D, Zhu YN, Wang XH, Lu YS, Wang YB, Zen K, Li LM. HIF-1alpha-induced miR-23a approximately 27 a approximately 24 cluster promotes colorectal cancer progression via reprogramming metabolism. Cancer Lett. 2019;440-441:211-22. https://doi.org/10.1016/j.ca nlet.2018.10.025.

41. Jing PY, Zhao N, Xie NL, Ye MX, Zhang Y, Zhang ZP, Li MY, Lai XF, Zhang J, Gu ZP. miR-24-3p/FGFR3 Signaling as a novel Axis is involved in epithelialMesenchymal transition and regulates lung adenocarcinoma progression. J Immunol Res. 2018:2018:2834109.

42. Lang B, Shang C, Meng LR. Targeted silencing of S100A8 gene by miR-24 to increase chemotherapy sensitivity of endometrial carcinoma cells to paclitaxel. Med Sci Monit. 2016;22:1953-8. https://doi.org/10.12659/MSM. 899179

\section{Publisher's Note}

Springer Nature remains neutral with regard to jurisdictional claims in published maps and institutional affiliations.

Ready to submit your research? Choose BMC and benefit from

- fast, convenient online submission

- thorough peer review by experienced researchers in your field

- rapid publication on acceptance

- support for research data, including large and complex data types

- gold Open Access which fosters wider collaboration and increased citations

- maximum visibility for your research: over $100 \mathrm{M}$ website views per year

At BMC, research is always in progress.

Learn more biomedcentral.com/submissions 